\title{
17-AAG enhances the cytotoxicity of flavopiridol in mantle cell lymphoma via autophagy suppression
}

\author{
Y. XIAO*, J. GUAN \\ Department of Hematology, Tongji Hospital, Tongji Medical College, Huazhong University of Science and Technology, Wuhan 430030,China \\ *Correspondence: Yixiao86@yeah.net
}

Received July 25, 2014 / Accepted November 3, 2014

\begin{abstract}
Flavopiridol, a cyclin-dependent kinase inhibitor (CDKI), shows promising anti-tumor activity in hematologic malignancies. However, Flavopiridol-induced protective autophagy may lead to drug resistance. Here we found that Hsp90 inhibitor 17-AAG can sensitize mantle cell lymphoma (MCL) cells to flavopiridol by suppressing flavopiridol-triggered protective autophagy. The suppressing effect of 17-AAG on autophgy was mediated by Beclin1 degradation and ERK inactivation. Furthermore, 17-AAG enhanced flavopiridol-induced apoptosis and growth suppression in MCL cells. Our study may provide some insights into CDKI -targeted chemotherapies.
\end{abstract}

Key words: flavopiridol, 17-AAG, MCL, autophagy

Mantle cell lymphoma (MCL), characterized by the $t(11 ; 14)$ (q13;q32) chromosomal translocation[1], is a heterogeneous subtype of non-Hodgkin lymphoma. Overexpression of cyclin D1 is the hallmark of MCL[2]. The constitutive expression of cyclin D1 accelerates the progression of MCL through deregulation of the cell cycle[3]. To facilitate orderly transition of cells and promote cell proliferation, cyclin D1 usually interacts with the cyclin-dependent kinases (CDKs) in cells[3]. Therefore, blockage of this biological interaction presents a good way for MCL therapy.

Flavopiridol, a broad CDK inhibitor (CDKI), inhibits CDK2, CDK4 and CDK6 but without a direct effect on protein stability[4]. Flavopiridol induces cell cycle arrest or apoptosis in malignant lymphocytes in vitro and in murine lymphoma models [5]. Flavopiridol also showed antitumor activity in various cancers such as myeloma [6], uterine leiomyoma [5], breast cancer[7] and some haematopoietic malignancies [8]. Flavopiridol has been already successfully administered to lymphoma patients in the clinic[9]. Flavopiridol has also been shown to have activity in patients with chronic lymphocytic leukemia (CLL) [10]. However, recent studies have shown that flavopiridol induced protective autophagy in CLL cells which may confer drug resistance to CDKI-targeted therapies[11, 12].

Hsp90 is an ATP-dependent molecular chaperon function as assisting protein folding and preventing nonfolding aggrega- tions of cells. Hsp90 is overexpressed in various types of cancer cells and is also a target for cancer therapy $[13,14]$. Moreover, Hsp90 can bind to and stabilize multiple autophagy-related proteins or kinases, such as Beclin1[15], Bcl-2 [16], Raf-1 [17], GABARAPL1[18] and Akt [19]. Therefore, inhibitors of Hsp90 may sensitize chemotherapeutics which induces protective autophagy in tumor cells. 17-allylaminogeldanamycin (17-AAG), one of the well-studied inhibitors of Hsp90, has been demonstrated to be effective in a spectrum of cancers by sensitizing other drugs both in vitro and in vivo [19-21]. Several phase-I to -III clinical trials have been undertaken to investigate the clinical efficacy and drug tolerance of 17-AAG, possibly to provide more evidence to tumor chemotherapy [22-24].

In our study for the first time was demonstrated that 17-AAG significantly enhanced the sensitivity of MCL cells to flavopiridol by enhancing apoptosis. We also found that 17-AAG inhibited flavopiridol-induced autophagy by suppressing ERK activation and Beclin1 stability. Presented study may provide a novel strategy for CDKI-targeted therapeutics.

\section{Materials and methods}

Cell lines and reagents. MCL cell lines JeKo-1 were purchased from ATCC (American Type Culture Collec- 
tion) and were passaged in our laboratory for less than 6 months. Cells were cultured in RPMI-1640 with 10\% FBS (fetal bovine serum) and antibiotics added in the steady environment of $37^{\circ} \mathrm{C}$ and $5 \% \mathrm{CO}_{2}$. Flavopiridol [(-)-cis-2(2-chlorophenyl)-5,7-dihydroxy-8-[4-(3-hydroxy-1-methyl) piperidinyl]-4H-1-benzopyran-4-one hydrochloride was from Sigma-Aldrich (Louis, MO, USA) and was dissolved in DMSO at $10 \mathrm{mM}$ as stock solution. 17-AAG was purchased from Santa Cruz Biotechnology (Santa Cruz, CA, USA) and dissolved in DMSO with 10mM as stock solution. 3-methyladenine (3-MA) was purchased from Sigma-Aldrich (Louis, MO, USA). Annexin-V and PI (Prodium Iodide) dyes were purchased from BD bioscience (BD, NJ, USA).

Western blot. Whole cell lysate were prepared and Western blot was performed as previously described [5]. Antibodies detecting Bcl-2 and Beclin1 were from Santa Cruz Biotechnology (Santa Cruz, CA, USA), and antibodies for PARP, Ulk-1, Atg10, phospho-Bcl-2, phospho-ERK1/2 and total-ERK were from Cell Signaling Technology (Boston, MA, USA). Antibody for LC3 was obtained from Sigma-Aldrich (Louis, MO, USA). Antibody of GAPDH was purchased from Beyotime Company (Shanghai, China).

Cell transfection. JeKo-1 cells were seeded to 6-well plate at $1 \times 10^{4}$. After overnight, $4 \mu \mathrm{g}$ pcDNA3 control plasmid DNA or pcDNA3-Beclin 1 plasmid DNA was mixed with $5 \mu \mathrm{L}$ Lipofectamine2000 in Opti-MEM (Invitrogen, Carlsbad, CA, USA) respectively according to the manufacturer's protocol. Cells were incubated in these mixtures for 6 hours and then normal RPMI-1640 with FBS was supplied for another 18 hours. Treatment of the corresponding group was added afterwards for another 24 hours.

Trypan blue exclusion study. The treated cells were adequately suspended and $0.4 \%(\mathrm{w} / \mathrm{v})$ trypan blue solution was added at a volume ratio (the cell suspension to the trypan blue solution) of 9:1. Subsequently, the cells were counted under an optical microscope. The cell failing to exclude the

A
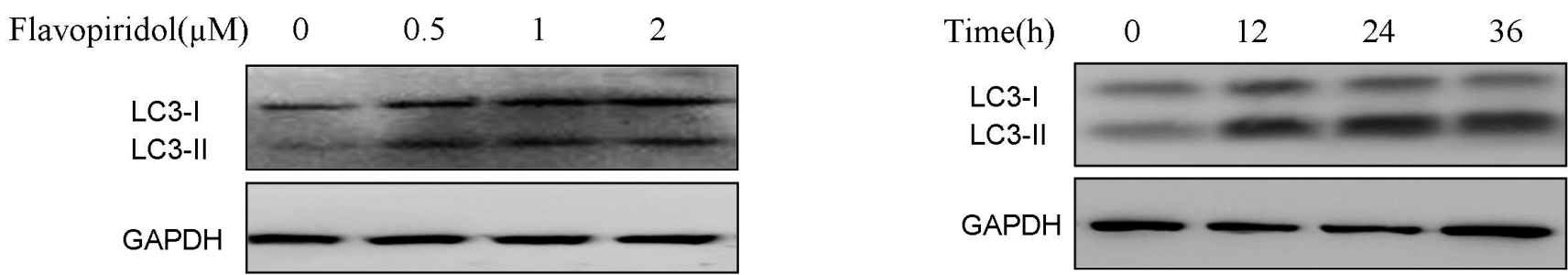

C
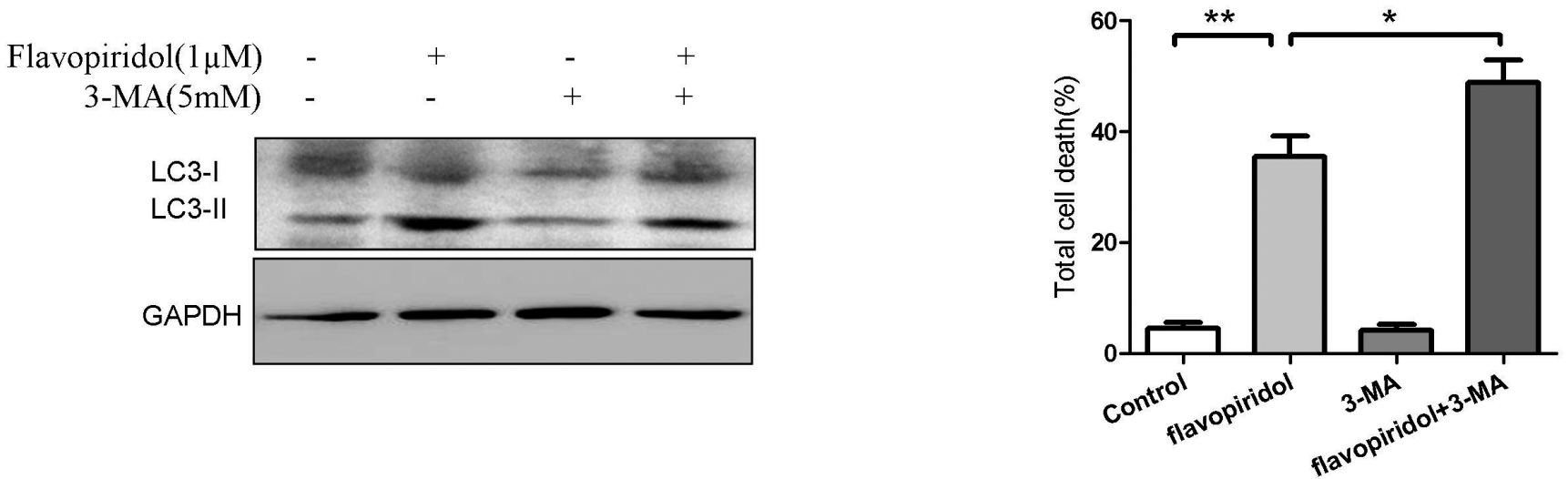

Figure 1. Flavopiridol induced protective autophagy in MCL cells.

(A) JeKo-1 cells were treated with flavopiridol at indicated dose for 24 hours, then the protein levels of LC3-I and LC3-II were detected by Western blot, taking GAPDH as a loading control. (B) JeKo-1 cells were treated with $1 \mu \mathrm{M}$ flavopiridol for indicated time, and then the protein levels of LC3-I and LC3-II were detected by Western blot, taking GAPDH as a loading control. (C) JeKo-1 cells were treated with as (B) for $24 \mathrm{~h}$, and total cell death was evaluated by trypan blue staining. Data were Mean \pm SD from three independent experiments. ${ }^{\star *}: P<0.01,{ }^{*}: P<0.05$. $(D)$ JeKo- 1 cells were treated with DMSO $(0.1 \% \mathrm{v} / \mathrm{v}), 1 \mu \mathrm{M}$ flavopiridol, $5 \mathrm{mM} 3-\mathrm{MA}$ or combined flavopiridol and 3-MA for 24h, and then the protein levels of LC3-I and LC3-II were detected by Western blot, taking GAPDH as a loading control. (E) JeKo-1 cells were treated as (C) for $48 \mathrm{~h}$, then total cell death was evaluated by trypan blue staining. Data were Mean \pm SD from three independent experiments. ${ }^{* *}: P<0.01,{ }^{*}: P<0.05$. 
dye presented blue and was definited as dead cell. The total death rate $(\%)=$ numbers of dead cells/( numbers of living cells + numbers of dead cells) $\times 100 \%$.

Cell viability assay. Cell viability assay was performed using CCK-8 kit (Dojindo, Shanghai, China) following protocol. OD450 of DMSO treatment group was used as the control group (100\%) compared with other groups.

Soft agar colony assays. $1000 \mathrm{JeKo}-1$ cells were mixed in $0.4 \%$ agarose containing RPMI-1640, 20\% FBS and $0.3 \%$ bacto agar, and plated on $0.6 \%$ agarose-coated $35-\mathrm{mm}$ dishes. After culturing for 14 days, colonies larger than $0.1 \mathrm{~mm}$ in diameter were counted.
Acridine orange staining. Staining cells with acridine orange was performed according to Yongqiang's procedures[25]. Briefly, the treated-cells were added with acridine orange at final concentration $1 \mathrm{mg} / \mathrm{ml}$ and incubated for $15 \mathrm{~min}$ at $37^{\circ} \mathrm{C}$. Then the cells were washed three times with PBS. After suspended in PBS, the cells was dropped on a glass slide and evaluated under fluorescence microscope [25].

Detection of apoptosis. Cells in different groups were treated for indicated times. They were digested with trypsin and washed with PBS once. Subsequently, cells were incubated with Annexin-V and PI (Prodium Iodide) for 30 minutes at room temperature. Flow cytometry was conducted to analyze

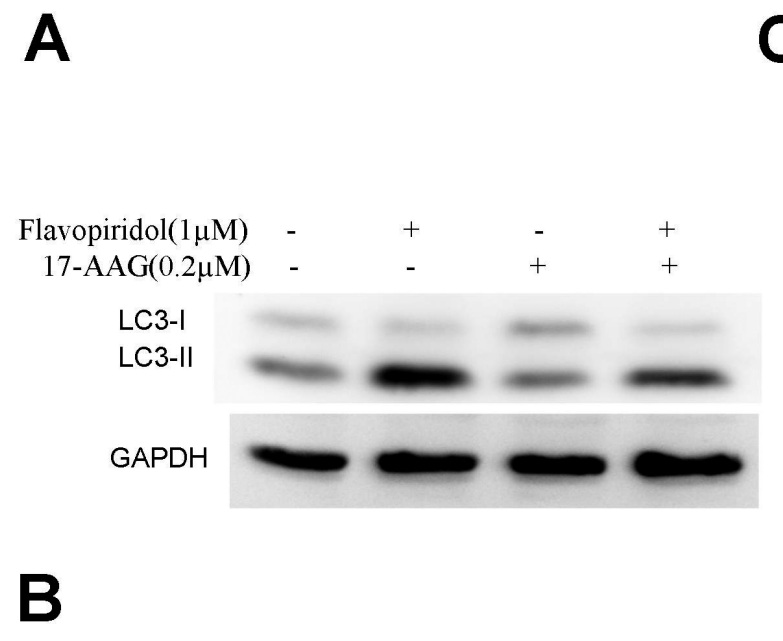

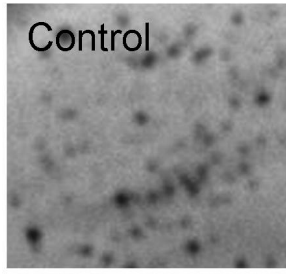
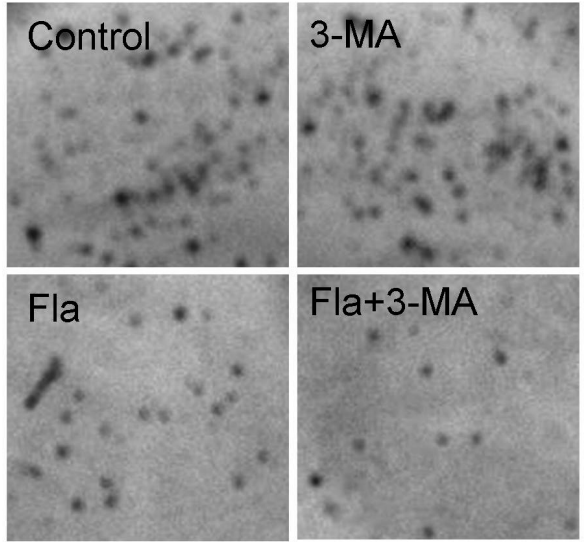
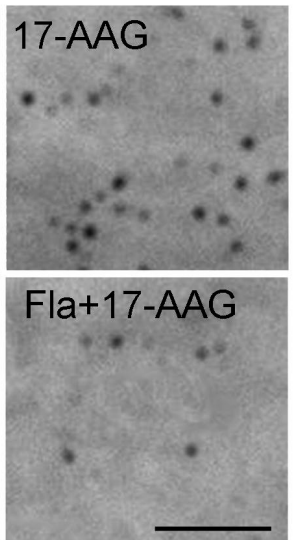
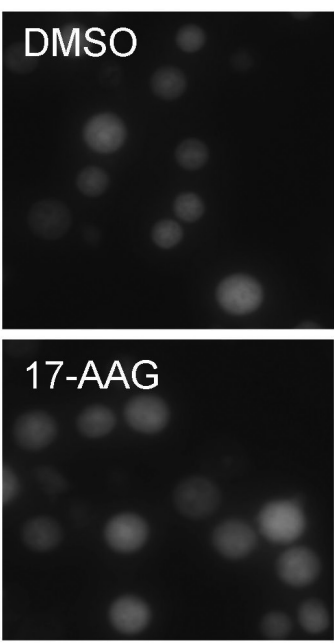
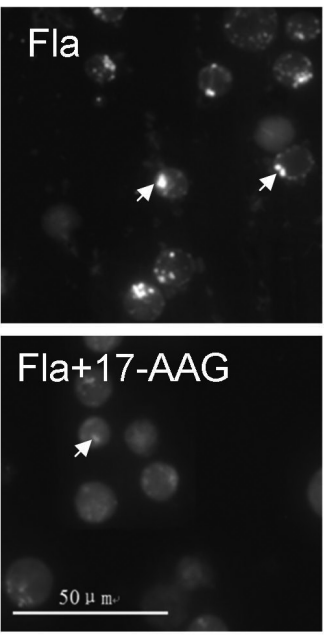

D

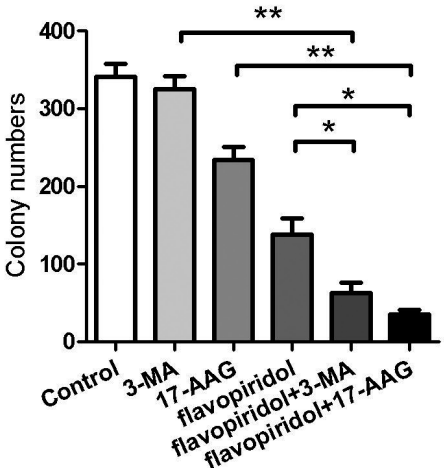

$\mathbf{E}$

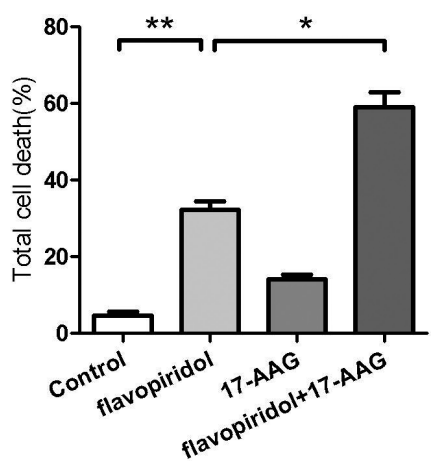

Figure 2 17-AAG suppressed flavopiridol-induced autophgy in MCL cells.

(A) JeKo-1 cells were treated with vehicle DMSO $(0.1 \% \mathrm{v} / \mathrm{v}), 1 \mu \mathrm{M}$ flavopiridol, $200 \mathrm{nM}$ 17-AAG or co-treatment of flavopiridol and 17-AAG for $24 \mathrm{~h}$, and then the protein levels of LC3-I/II were detected by Western blot, taking GAPDH as a loading control. (B) JeKo-1 cells were treated as (A), then AVOs formation were assessed by acridine orange staining. The white arrows show the positive autophagic vacuoles. (C) A total of 1000 JeKo-1 cells in $0.4 \%$ agarose containing DMSO $(0.1 \% \mathrm{v} / \mathrm{v}), 1 \mu \mathrm{M}$ flavopiridol, $5 \mathrm{mM}$ 3-MA, 200nM 17-AAG, combined flavopiridol and 3-MA or combined flavopiridol and 17-AAG were seeded on soft agar in $35-\mathrm{mm}$ dishes respectively, and colonies larger than $0.1 \mathrm{~mm}$ were counted after incubation for 2 weeks. Representative colonies are shown in the photographs. (D) The average numbers of colonies in triplicate experiments are plotted. ${ }^{* *}: P<0.01,{ }^{*}: P<0.05$. (E) JeKo- 1 cells were treated as (A) for $48 \mathrm{~h}$, then total cell death was evaluated by trypan blue staining. Data were Mean \pm SD from three independent experiments. ${ }^{* *}: P<0.01,{ }^{*}: P<0.05$. 
the values of fluorescence of each cell, and statistical diagrams were drawn by FlowJo 7.5.

Statistical analysis. The data are presented as Mean \pm SD from triplicate experiments. Two-way t-test and ANOVA were used to analyze the variance in different treatment groups for possible significance. A threshold of $P<0.05$ was defined as statistically significant.

\section{Results}

Flavopiridol induced protective autophagy in MCL cells. First we investigate whether flavopiridol induces autophagy in MCL cells by assessing autophagy induction through examining the accumulation of LC3-II. During autophagy, the soluble LC3-I is lipidated as LC3-II and translocated to autophagosome membranes. LC3-II is a widely-used marker of autophagy because it makes LC3 protein shift from diffuse to punctate staining and has higher electrophoretic mobility on gels compared to LC3-I [26]. As shown in Fig. 1A and B, $0.5 \mu \mathrm{M}$ or more flavopiridol induced significant LC3-II accumulation after treatment for over $12 \mathrm{~h}$ in JeKo- 1 cells. The autophagy inhibitor 3-MA obviously represses flavopiridolinduced autophagy (Fig. 1C). Moreover, 3-MA increased the cytotoxicity of flavopiridol in JeKo-1 cells (Fig. 1D). These data indicate that flavopiridol induces protective autophagy in JeKo-1 cells.

17-AAG suppressed flavopiridol-induced autophgy in MCL cells. To test whether inhibition of HSP90 can suppress flavopiridol-induced augophagy, we treated JeKo-1 cells with 17-AAG and flavopiridol. As shown in Fig. 2A, 17-AAG co-treatment significantly attenuated flavopiridol-induced LC3-II accumulation in JeKo-1 cells. Flavopiridol treatment triggered acidic vesicular organelle (AVO) formation was also suppressed by 17-AAG co-treatment (Fig. 2B). These data demonstrated that 17-AAG suppressed flavopiridol-induced autophagy in MCL cells. Moreover, either flavopiridol plus 3-MA or flavopiridol plus 17-AAG produced a significantly lower numbers of colonies in soft agar than flavopiridol alone (Fig. 2C and 2D). Furthermore, combination of flavopiridol and 17-AAG dramatically increased flavopiridol-induced total cell death in JeKo-1 cells ( Fig. 2E).These results indicate that 17-AAG sensitizes flavopiridol through autophagy suppression in MCL cells.

17-AAG promoted Beclin1 degradation and ERK inactivation. To figure out the mechanisms of 17-AAGinduced autophagy suppression, we check the protein level
A

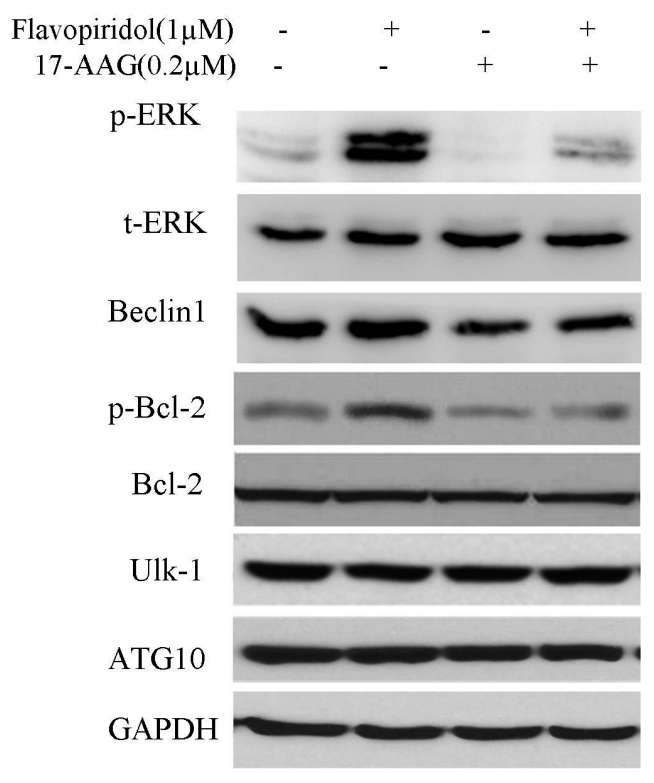

B

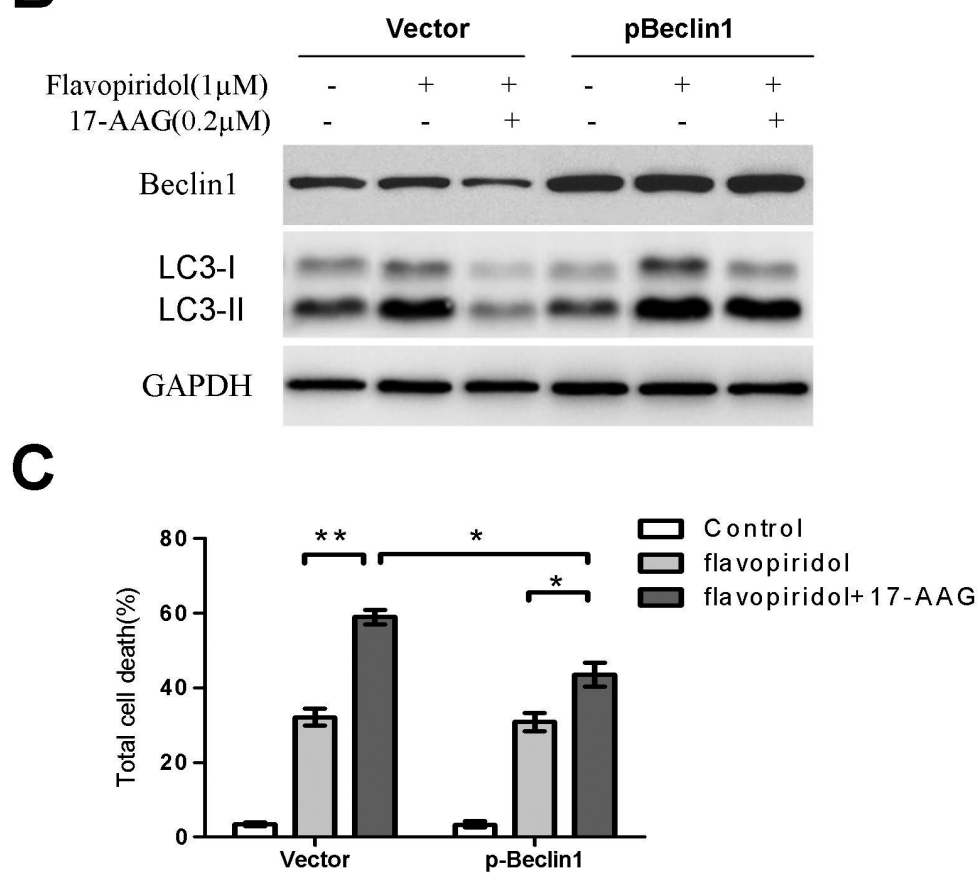

Figure 3 17-AAG promoted Beclin1 degradation and ERK inactivation.

(A) JeKo-1 cells were treated with vehicle DMSO $(0.1 \% \mathrm{v} / \mathrm{v}), 1 \mu \mathrm{M}$ flavopiridol, 200nM 17-AAG or co-treatment of flavopiridol and 17-AAG for $24 \mathrm{~h}$, and then the protein levels of $\mathrm{p}$-ERK, $\mathrm{t}-\mathrm{ERK}$, $\mathrm{p}$-Bcl-2, $\mathrm{t}$-Bcl-2, Beclin1, Ulk-1 and ATG10 were detected by Western blot, taking GAPDH as a loading control. (B) JeKo-1 cells were transfected with pcDNA3 control vector or pcDNA3-Beclin 1 vector, after overnight cells were treated with vehicle DMSO $(0.1 \% \mathrm{v} / \mathrm{v}), 1 \mu \mathrm{M}$ flavopiridol, 200nM 17-AAG or combined flavopiridol and 17-AAG for another $24 \mathrm{~h}$, and then the protein levels of Beclin1 and LC3-I/II were detected by Western blot. (C) JeKo- 1 cells were treated as (B) for $48 \mathrm{~h}$, then total cell death was evaluated by trypan blue staining. Data were Mean \pm SD from three independent experiments. ${ }^{* *}: P<0.01,{ }^{*}: P<0.05$. 
of several HSP90 client proteins which are closely related to autophagy. As shown in Figure 3A, 17-AAG obviously decreased the level of p-ERK, p-Bcl-2 and Beclin1 while has no effect on the level of total ERK, total Bcl-2, ulk-1 and ATG10. ERK is a downstream target of Raf-1, an important client protein of HSP90 [27]. It is reported that ERK-mediated Bcl-2 phosphorylation could potentiate the abrogation between Bcl-2 and Beclin 1 and enhance autophagy induction $[28,29]$. So $17-A$ AG-mediated ERK inactivation could influence the interaction between Bcl-2 and Beclin 1 by decreasing Bcl-2 phosphorylation. In addi- tion, Beclin1, a crucial protein for autophagy induction, is also the client protein of HSP90. Overexpression of Beclin 1 eliminated the effect of 17-AAG on flavopiridol-induced LC3-II accumulation and total cell death (Fig. 3B and 3C). It is notable that flavopiridol-induced autophagy can't be further enhanced by Beclin1 overexpression (Fig. 3B), while the suppression of 17-AAG on flavopiridol-induced autophagy can be compensated by Beclin 1 overexpression (Fig. 3B). Therefore, overexpression of Beclin 1 can't influence flavopiridol-induced cell death while decreases the effect of 17-AAG on the same item (Fig. 3C). These

A

B

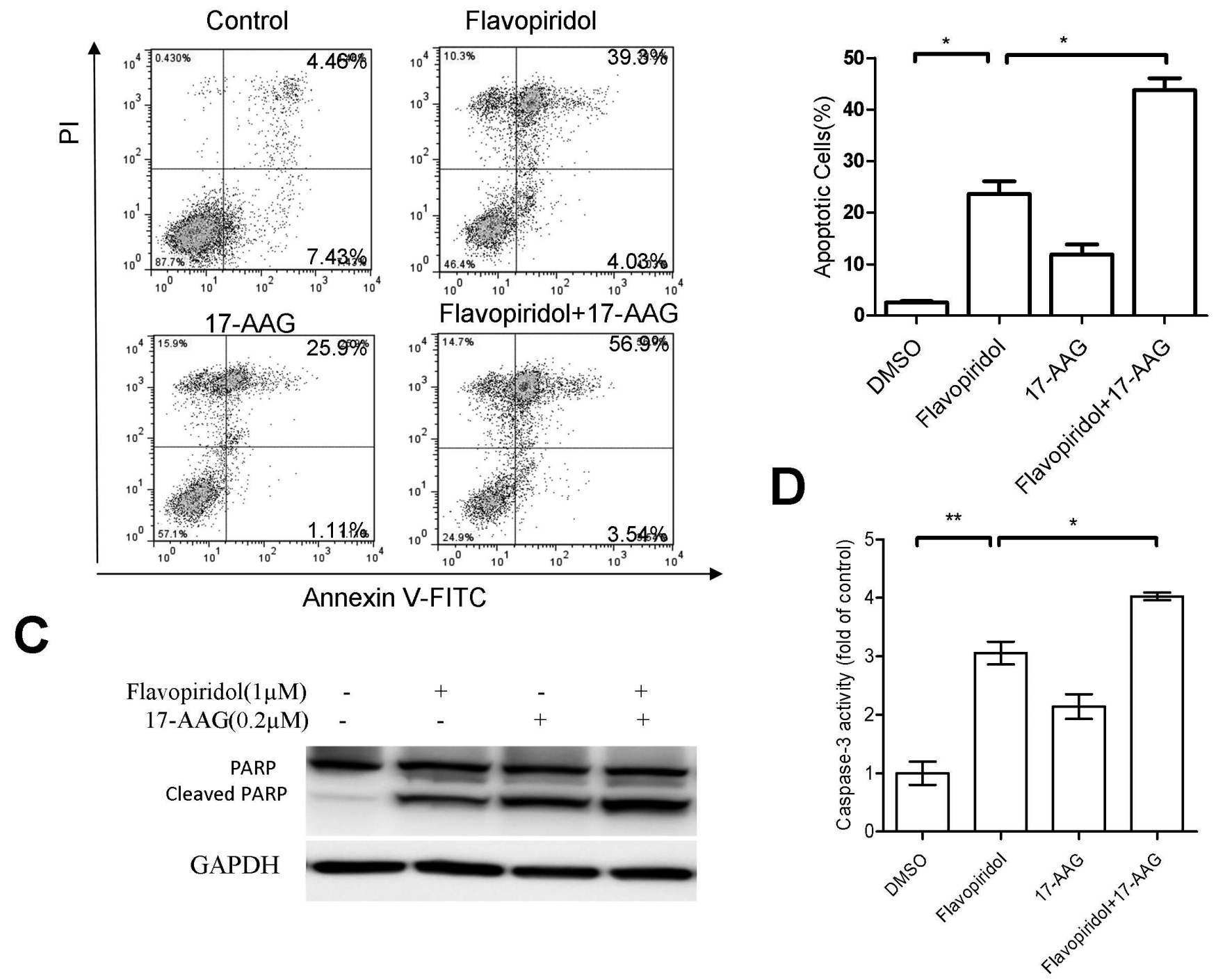

Figure 4 17-AAG enhanced flavopiridol-induced apoptosis in MCL cells.

(A, B) JeKo-1 cells were treated with vehicle DMSO $(0.1 \% \mathrm{v} / \mathrm{v}), 1 \mu \mathrm{M}$ flavopiridol, $200 \mathrm{nM}$ 17-AAG or co-treatment of flavopiridol and 17-AAG for $48 \mathrm{~h}$, and then they were stained with Annexin V-FITC/PI and analyzed by flow cytometry, results from three tests were quantified to analyze the statistically significance. ${ }^{\star *}: P<0.01,{ }^{\star}: P<0.05$. (C) JeKo-1 cells were treated as (A), then the protein levels of PARP were detected by Western blot, taking GAPDH as a loading control. (D) JeKo-1 cells were treated as (A), then the caspase 3 activity was analyzed. ${ }^{* *}: P<0.01,{ }^{\star}: P<0.05$. 
date demonstrated that 17-AAG suppressed flavopiridolinduced autophagy through promoting Beclin 1 degradation and ERK inactivation in MCL cells.

17-AAG enhanced flavopiridol-induced apoptosis in MCL cells. We next investigated whether apoptosis contributes to the combined treatment-induced cell death. Annexin-PI staining analysis found that co-treatment with flavopiridol and 17-AAG significantly increased the rate of apoptotic cells (Fig. 4A and 4B), which was further validated by enhanced PARP cleavage (a substrate of caspase 3, Fig. 4C) and increased caspase 3 activity (Fig 4D). These results indicated that Hsp90 inhibitor 17-AAG could potentiate flavopiridol-mediated cell death by modulating apoptosis in MCL cells.

\section{Discussion}

CDK inhibitor flavopiridol shows promising anti-tumor efficacy in several kinds of tumors. However, it was demonstrated that CLL cells are relatively resistant to flavopiridol. Moreover, protective autophagy may contribute to this resistance. In the present study, we demonstrated for the first time that co-treatment of CDK inhibitor flavopiridol and Hsp90 inhibitor 17-AAG exhibited synergetic efficacy in killing MCL cells. 17-AAG attenuated flavopiridol-induced protective autophagy by inhibiting ERK-mediated Bcl-2 phosphorylation and promoting Beclin1 degradation.

Autophagy is a self-digesting process characterized by formation of double-membrane autophagosome in the cytoplasm. Degradation of contents in autophagosome provides energy and nutrients to cells and protects cells from stress. Generally, autophagy promotes tumor cell survival and decreases sensitivity to chemotherapy [30]. Inhibition of autophagy can sensitize tumors to both chemotherapy and radiotherapy [31]. Previous data have demonstrated that flavopiridol induce autophagy and ER stress. So in this study we wanted to suppress autophagy by targeting molecular chaperones, which is responsible for stabilization of multiple oncogenes or autophagy-related genes in tumors.

As to the mechanisms of 17-AAG attenuating flavopiridolinduced protective autophagy, consistent to previous study [15], Beclin1 protein level decreased upon co-treatment of flavopiridol and 17-AAG or 17-AAG alone. Overexpression of Beclin1 eliminates the effect of 17-AAG on flavopiridolinduced autophagy and total cell death. These results indicate that Beclin1 plays a key role in the process of 17-AAG sensitizing flavopiridol in MCL cells. The interaction of Bcl-2 and Beclin 1 also affects autophagy induction. Bcl-2 could be phosphorylated at several sites by ERK and Bcl-2 phosphorylation could promote its detachment with Beclin1 and enhance autophagy induction[28]. Consistent with previous reports, inhibition of Hsp90 significantly inhibits ERK phosphorylation and $\mathrm{Bcl}-2$ phosphorylation [17, 32]. These results indicated that 17-AAG also attenuated flavopiridolinduced autophagy by suppressing ERK-mediated Bcl-2 phosphorylation.
Results from this study may also have also therapeutic implications. Recently, the synergistic effects of autophagy inhibitors and CDKI have been reported in cancer therapy[33]. However, due to complementary activating pathways, deceased drug sensitivity always happened simply by inhibiting a single signaling pathway. Our results demonstrated that, by targeting molecular chaperone Hsp90, a significantly synergistic anti-tumor effect was observed by suppressing flavopiridol-induced protective autophagy in MCL cells. Our study may provide a novel strategy for CDKI-targeted therapeutics.

Acknowlegments: This study was supported in part by Natural Science Foundation of Hubei Province (No. 2012FFB02435) and the central university special funding (No. 2013QN191).

\section{Refferences}

[1] HARRIS N, JAFFE E, DIEBOLD J, FLANDRIN G, MULLER-HERMELINK H, et al. World Health Organization classification of neoplastic diseases of the hematopoietic and lymphoid tissues: report of the Clinical Advisory Committee meeting. Journal of clinical oncology 1999; 17: 3835-3849.

[2] ZUCCA E, STEIN H, COIFFIER B. European Lymphoma Task Force (ELTF): Report of the workshop on Mantle Cell Lymphoma (MCL). Annals of oncology 1994; 5: 507-511.

[3] MASSAGUE J. G1 cell-cycle control and cancer. Nature 2004; 432: 298-306. http://dx.doi.org/10.1038/nature03094

[4] GRANT S, DENT P. Gene profiling and the cyclin-dependent kinase inhibitor flavopiridol: what's in a name? Molecular cancer therapeutics 2004; 3: 873-875.

[5] LEE H, BAEK J, SHIN S, KWON S, CHA S, et al. Antitumor Effects of Flavopiridol on Human Uterine Leiomyoma In Vitro and in a Xenograft model. Reprod Sci 2014; 21: 1153-1160. http://dx.doi.org/10.1177/1933719114525266

[6] HOFMEISTER C, POI M, BOWERS M, ZHAO W, PHELPS $\mathrm{M}$, et al. A phase I trial of flavopiridol in relapsed multiple myeloma. Cancer chemotherapy and pharmacology 2014; 73: 249-257. http://dx.doi.org/10.1007/s00280-013-2347-y

[7] HICKS M, HU Q, MACRAE E, DEWILLE J. JUNB promotes the survival of Flavopiridol treated human breast cancer cells. Biochemical and biophysical research communications 2014; 450: 19-24. http://dx.doi.org/10.1016/j.bbrc.2014.05.057

[8] KITADA S, ZAPATA J, ANDREEFF M, REED J. Protein kinase inhibitors flavopiridol and 7-hydroxy-staurosporine down-regulate antiapoptosis proteins in B-cell chronic lymphocytic leukemia. Blood 2000; 96: 393-397.

[9] JONES J, RUPERT A, POI M, PHELPS M, ANDRITSOS L, et al. Flavopiridol can be safely administered using a pharmacologically derived schedule and demonstrates activity in relapsed and refractory non-Hodgkins lymphoma. American journal of hematology 2014; 89: 19-24. http://dx.doi. org/10.1002/ajh.23568

[10] BLACHLY J, BYRD J. Emerging drug profile: cyclin-dependent kinase inhibitors. Leukemia \& lymphoma 2013; 54: 2133-2143. http://dx.doi.org/10.3109/10428194.2013.783911 
[11] MAHONEY E, BYRD J, JOHNSON A. Autophagy and ER stress play an essential role in the mechanism of action and drug resistance of the cyclin-dependent kinase inhibitor flavopiridol. Autophagy 2013; 9: 434-435. http://dx.doi. org/10.4161/auto.23027

[12] MAHONEY E, LUCAS D, GUPTA S, WAGNER A, HERMAN S, et al. ER stress and autophagy: new discoveries in the mechanism of action and drug resistance of the cyclin-dependent kinase inhibitor flavopiridol. Blood 2012; 120: 1262-1273. http://dx.doi.org/10.1182/blood-2011-12$\underline{400184}$

[13] YUFU Y, NISHIMURA J, NAWATA H. High constitutive expression of heat shock protein 90 alpha in human acute leukemia cells. Leuk Res 1992; 16: 597-605. http://dx.doi. org/10.1016/0145-2126(92)90008-U

[14] FERRARINI M, HELTAI S, ZOCCHI M, RUGARLI C. Unusual expression and localization of heat-shock proteins in human tumor cells. Int J Cancer 1992; 51: 613-619. http:// dx.doi.org/10.1002/ijc.2910510418

[15] XU C, LIU J, HSU L, LUO Y, XIANG R, et al. Functional interaction of heat shock protein 90 and Beclin 1 modulates Toll-like receptor-mediated autophagy. FASEB J 2011; 25: 2700-2710. http://dx.doi.org/10.1096/f..10-167676

[16] COHEN-SAIDON C, CARMI I, KEREN A, RAZIN E. Antiapoptotic function of $\mathrm{Bcl}-2$ in mast cells is dependent on its association with heat shock protein 90beta. Blood 2006; 107: 1413-1420. http://dx.doi.org/10.1182/blood-2005-07-2648

[17] SCHULTE T, BLAGOSKLONNY M, ROMANOVA L, MUSHINSKI J, MONIA BP, et al. Destabilization of Raf- 1 by geldanamycin leads to disruption of the Raf-1-MEK-mitogenactivated protein kinase signalling pathway. Mol Cell Biol 1996; 16: 5839-5845.

[18] SEGUIN-PY S, CROIZIER S, CHAKRAMA F, DESPOUY G, LE GRAND J, et al. Identification of HSP90 as a new GABARAPL1 (GEC1)-interacting protein. Biochimie 2012; 94: 748-758. http://dx.doi.org/10.1016/j.biochi.2011.11.006

[19] SOLIT D, BASSO A, OLSHEN A, SCHER H, ROSEN N. Inhibition of heat shock protein 90 function down-regulates Akt kinase and sensitizes tumors to Taxol. Cancer Res 2003; 63: 2139-2144.

[20] MCCOLLUM A, LUKASIEWICZ K, TENEYCK C, LINGLE W, TOFT DO, et al. Cisplatin abrogates the geldanamycininduced heat shock response. Mol Cancer Ther 2008; 7: 3256-3264. http://dx.doi.org/10.1158/1535-7163.MCT-08$\underline{0157}$

[21] YIN X, ZHANG H, LUNDGREN K, WILSON L, BURROWS F, et al. BIIB021, a novel Hsp90 inhibitor, sensitizes head and neck squamous cell carcinoma to radiotherapy. Int J Cancer 2010; 126: 1216-1225.

[22] TSE A, KLIMSTRA D, GONEN M, SHAH M, SHEIKH T, et al. A phase 1 dose-escalation study of irinotecan in combination with 17-allylamino-17-demethoxygeldanamycin in patients with solid tumors. Clin Cancer Res 2008; 14 : 6704-6711. http://dx.doi.org/10.1158/1078-0432.CCR-08$\underline{1006}$
[23] RAMALINGAM S, EGORIN M, RAMANATHAN R, REMICK S, SIKORSKI R, et al. A phase I study of 17-allylamino-17-demethoxygeldanamycin combined with paclitaxel in patients with advanced solid malignancies. Clin Cancer Res 2008; 14: 3456-3461. http://dx.doi.org/10.1158/1078-0432. CCR-07-5088

[24] MODI S, LINDEN H, SOLIT D, CHANDARLAPATY S, ROSEN N, et al. HSP90 inhibition is effective in breast cancer: a phase II trial of tanespimycin (17-AAG) plus trastuzumab in patients with HER2-positive metastatic breast cancer progressing on trastuzumab. Clin Cancer Res 2011; 17: 5132-5139. http://dx.doi.org/10.1158/1078-0432.CCR-11-0072

[25] CHEN Y, AZAD M, GIBSON S. Methods for detecting autophagy and determining autophagy-induced cell death. Can J Physiol Pharmacol 2010; 88: 285-295. http://dx.doi. org/10.1139/Y10-010

[26] MAIURI M, CRIOLLO A, TASDEMIR E, VICENCIO J, TAJEDDINE N, et al. $\mathrm{BH} 3$-only proteins and $\mathrm{BH} 3$ mimetics induce autophagy by competitively disrupting the interaction between Beclin 1 and Bcl-2/Bcl-X(L). Autophagy 2007; 3: 374-376. http://dx.doi.org/10.4161/auto.4237

[27] SOGA S, AKINAGA S, SHIOTSU Y. Hsp90 inhibitors as anti-cancer agents, from basic discoveries to clinical development. Curr Pharm Des 2013; 19: 366-376. http://dx.doi. org/10.2174/138161213804143617

[28] XIAO D, CHOI S, JOHNSON D, VOGEL V, JOHNSON $\mathrm{C}$, et al. Diallyl trisulfide-induced apoptosis in human prostate cancer cells involves c-Jun N-terminal kinase and extracellular-signal regulated kinase-mediated phosphorylation of Bcl-2. Oncogene 2004; 23: 5594-5606. http://dx.doi. org/10.1038/sj.onc.1207747

[29] NI Z, WANG B, DAI X, DING W, YANG T, LI X, et al. HCC cells with high levels of Bcl-2 are resistant to ABT-737 via activation of the ROS-JNK-autophagy pathway. Free Radic Biol Med 2014; 70: 194-203. http://dx.doi.org/10.1016/j. freeradbiomed.2014.02.012

[30] YANG Z, KLIONSKY D. Eaten alive: a history of macroautophagy. Nat Cell Biol 2010; 12: 814-822. http://dx.doi. org/10.1038/ncb0910-814

[31] MAIURI M, ZALCKVAR E, KIMCHI A, KROEMER G. Self-eating and self-killing: crosstalk between autophagy and apoptosis. Nat Rev Mol Cell Biol 2007; 8: 741-752. http:// dx.doi.org/10.1038/nrm2239

[32] STANCATO L, SILVERSTEIN A, OWENS-GRILLO J, CHOW Y, JOVE R, et al. The hsp90-binding antibiotic geldanamycin decreases Raf levels and epidermal growth factor signaling without disrupting formation of signaling complexes or reducing the specific enzymatic activity of Raf kinase. J Biol Chem 1997; 272: 4013-4020. http://dx.doi. org/10.1074/jbc.272.7.4013

[33] EL-KHOURY V, PIERSON S, SZWARCBART E, BRONS N, ROLAND O, et al. Disruption of autophagy by the histone deacetylase inhibitor MGCD0103 and its therapeutic implication in B-cell chronic lymphocytic leukemia. Leukemia 2014; 28: 1636-1646. http://dx.doi.org/10.1038/leu.2014.19 